\title{
Fome de quê? A [in]visibilidade de meninas e mulheres interditadas de atuarem na Educação das áreas Exatas
}

\section{Hungry for what? The (in)visibility of girls and women prevented from acting in Hard-Science Education}

Duliana Boanova Souza'

Rochele de Quadros Loguercio²

\author{
'Universidade Federal do Rio Grande do Sul (UFRGS), Programa de Pós-Graduação Educação \\ em Ciências, Porto Alegre, RS, Brasil. Autora Correspondente: juliana.boanova@ufrgs.br \\ 2Universidade Federal do Rio Grande do Sul (UFRGS), Instituto de Química, Porto Alegre, RS, Brasil.
}

Resumo: Este artigo tem como objetivo problematizar a minoria feminina nas áreas de Ciência, Tecnologia, Engenharia e Matemática e verificar como se dá o incentivo às meninas e mulheres, principalmente na área da Educação Matemática. Para isso, analisamos o documento da Organização das Nações Unidas para a Educação, a Ciência e a Cultura (UNESCO) intitulado Decifrar o código, que relata como está ocorrendo a inserção das mulheres nessas áreas e divulga o panorama da participação e do desempenho das meninas ao redor de todas as regiões do mundo, identificando fatores influenciadores nos âmbitos individual, familiar, escolar e social. Este documento faz parte da agenda global, que tem como foco alcançar 30 objetivos específicos, sendo o $5^{\circ}$ a promoção da igualdade de gênero. Assim, é possível dizer que a escolha da minoria feminina não ocorre por acaso e que os principais âmbitos influenciadores podem desconstruir essa realidade.

Palavras-chave: Educação matemática; Mulheres; Igualdade de gênero; UNESCO; Agenda global.

Abstract: The present paper aims to problematize the feminine minority in the fields of Science, Technology, Engineering and Mathematics, as well as how girls and women are (not) encouraged to engage in such fields, especially in Mathematics Education. In order to achieve this goal, the document by the United Nations Organization for Education, Science and Culture (UNESCO), entitled Cracking the code has been analyzed. That document describes how women are being inserted in these fields by drawing a panorama of girls' participation and performance from every region, thus identifying some influential factors concerning individual, family, school, and social aspects. The document integrates the global agenda, which focuses on achieving 30 specific goals, the 5th of which is the promotion of gender equality. Thus, it is possible to affirm that the interest in female minority is not random, and that the main factors at play can deconstruct this reality.

Keywords: Mathematics education; Women; Gender equality; UNESCO; Global agenda.

Recebido em: 18/08/2020

Aprovado em: 01/09/2021 


\section{Introdução: agenda global}

A inquietação para a realização deste ensaio surgiu a partir de situações cotidianas vivenciadas de discriminação e preconceito direcionados a mulheres no mundo acadêmico, principalmente na área das Ciências Exatas. Salientamos que, por vezes, essas situações se tornam tão frequentes com as mulheres de determinadas áreas do saber, que se naturalizam e passam despercebidas, ainda que a temática seja uma constante nas pesquisas de diversas áreas.

O presente artigo ganhou potência após leituras sobre teorias de gênero e estudos sobre mulheres na ciência, que evidenciam as práticas generificadas que insistem em um apagamento do sujeito cientista e de um ocultamento das relações de poder do campo, que de tantas formas invisibilizou, particularmente, as mulheres.

A temática é global, urgente, e a Organização das Nações Unidas para a Educação, a Ciência e a Cultura (UNESCO) publicou um relatório com dados sobre mulheres nas áreas de Ciência, Tecnologia, Engenharia e Matemática (STEM), no qual os discursos e práticas ganham maior visibilidade e exibem a desigualdade de gênero. A organização construiu uma agenda global que possui 17 objetivos de desenvolvimento sustentável (figura 1) e, entre esses objetivos, o $5^{\circ}$ é promover a lgualdade de Gênero.

Figura 1 - 17 Objetivos da agenda global
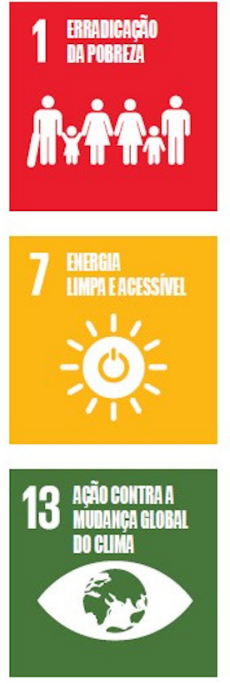
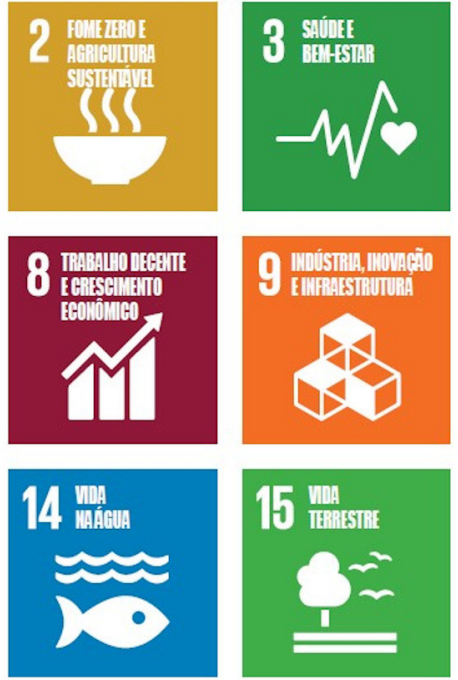

Fonte: Nações Unidas Brasil (2021).
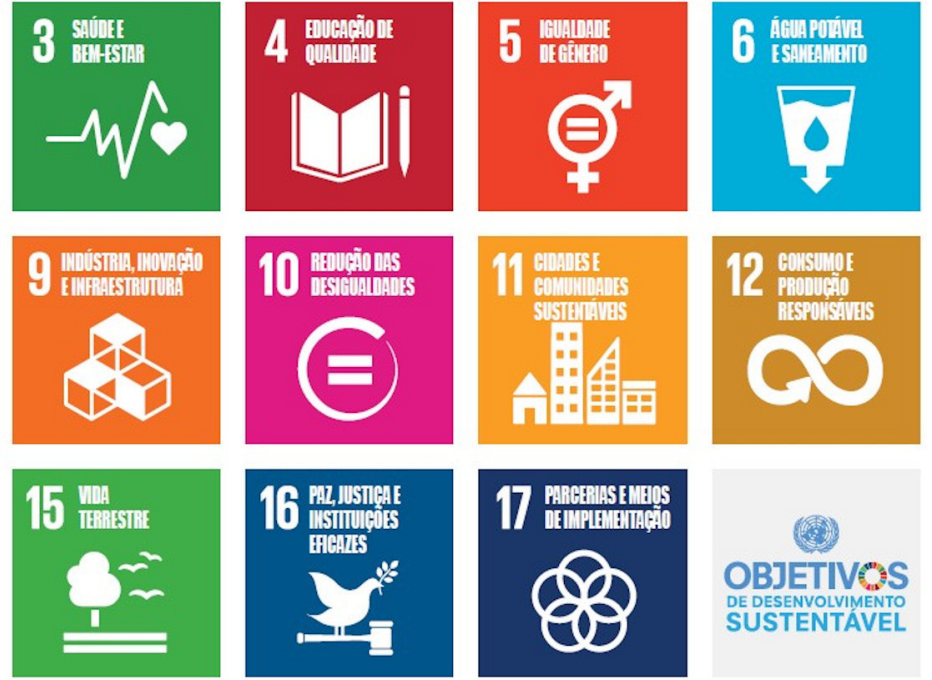

(9)

OBJETIVOS DEDESENOLIVMENTO

Figura 2 - Objetivo 5: igualdade de gênero

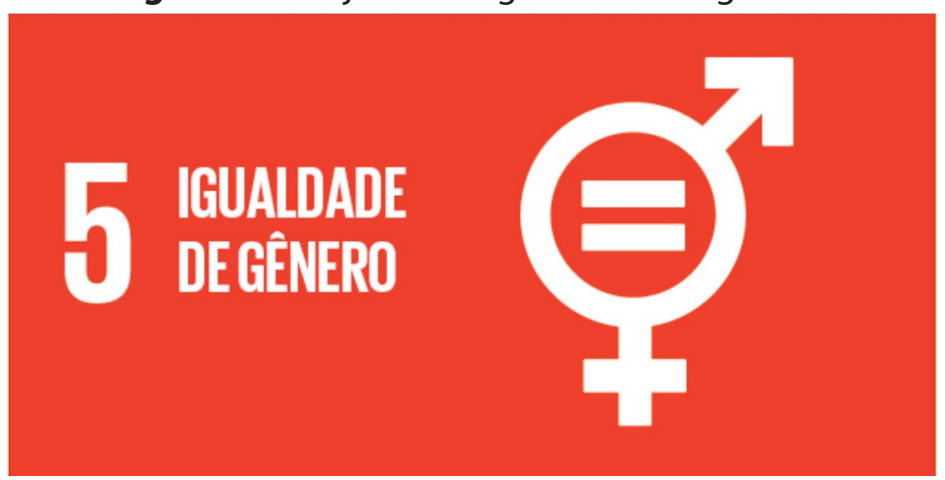

Fonte: Nações Unidas Brasil (2021). 
O documento divulga dados que comparam os números de mulheres e homens nas áreas de Ciência, Tecnologia, Engenharia e Matemática (STEM). No primeiro movimento, o texto explicita a desigualdade, destacando que, de 589 prêmios Nobel nas áreas de Física, Química e Medicina, apenas 17 foram conferidos a mulheres. Também comprova a minoria feminina na ciência, afirmando que apenas $28 \%$ dos pesquisadores do mundo são mulheres.

O relatório visa a estimular o debate e fundamentar políticas e programas em STEM, nos âmbitos mundial, regional e nacional. De forma específica, o relatório visa a: i) documentar a situação da participação, dos resultados de aprendizagem e dos avanços de meninas e mulheres na educação em STEM; ii) "decifrar o código", ou seja, analisar os fatores que contribuem para a participação, o desempenho e o avanço de meninas e mulheres na educação em STEM; e iii) identificar medidas que promovam o interesse e o envolvimento de meninas e mulheres nos estudos nas áreas de STEM (UNESCO, 2018, p.16).

A UNESCO se preocupa com a realidade da quantidade minoritária de mulheres que contemplam as áreas exatas e, segundo o documento, essa minoria não ocorre por acaso: "Muitas meninas são impedidas de se desenvolver por conta da discriminação, pelos diversos vieses e por normas e expectativas sociais que influenciam a qualidade da educação que elas recebem, bem como os assuntos que elas estudam" (UNESCO, 2018, p. 10).

A inserção de mulheres nas áreas de STEM reforça uma perspectiva sobre o fato de as mulheres serem desestimuladas a realizar atividades na área. Para a UNESCO, - adequado seria iniciar um processo de formação de professores direcionada à desconstrução do discurso patriarcal desde as séries iniciais, pois, embora o número de mulheres na população seja maior, ainda é perceptível um menor investimento na formação delas. De acordo com o documento,

[...] pesquisas sobre fatores biológicos, incluindo sobre a estrutura e o desenvolvimento do cérebro, genética, neurociência e hormônios, mostram que a disparidade de gênero em STEM (Ciência, Tecnologia, Engenharia e Matemática) não é resultado de diferenças entre os sexos relacionadas a esses fatores, ou a habilidades inatas. Em vez disso, os achados sugerem que a aprendizagem é fundamentada na neuroplasticidade, a capacidade que o cérebro tem de se expandir e formar novas conexões, e o desempenho na educação, incluindo em disciplinas de STEM, é influenciado pela experiência e pode ser melhorado por meio de intervenções direcionadas. As habilidades espaciais e linguísticas, em particular da língua escrita, apresentam uma correlação positiva com o desempenho em Matemática e podem ser melhoradas com a prática, independentemente do sexo, especialmente durante os primeiros anos de vida de uma pessoa (UNESCO, 2018, p. 11).

Sobre corpos generificados, as divergências entre corpos femininos e masculinos e suas problematizações permite inferir que a ciência foi seguindo seus caminhos e chegou na corporeidade, colocando-se agora, desde que conhecemos os gametas, com uma forma de animismo generalizado, constituindo as células com características culturais humanas, discutindo a passividade e o protagonismo típico de uma sociedade para dentro dos corpos. O embate é a fecundação, já que a sociedade androcêntrica postulava, via conhecimento acadêmico, que o espermatozóide é o gameta ativo e o óvulo passivo, o que afetou socialmente e culturalmente as mulheres. Além disso, no livro The evolution of sex, lançado pelo biólogo Patrick Geddes e pelo naturalista John 
Arthur Thomson em 1889, os autores afirmam que a diferença entre os aparelhos reprodutivos dos sexos fez com que a sociedade constituísse o sujeito mulher tal como o entendimento dos gametas, ou seja, como um ser totalmente passivo, o que implicaria um ciclo vicioso (THOMSON; GEDDES, 1889). Assim, cientistas definem os gametas com um olhar viciado e produzem culturalmente um entendimento de que as mulheres se comportam como gametas.

Essa passividade não se restringiria às questões fisiológicas, como indicavam os autores, pois o entendimento das mulheres como passivas lhes acomodava na sociedade como dependentes de seu oposto, o homem ativo, inclusive no que concerne a decisões de cunho social. Porém, as teorias que inferiorizavam as mulheres, pelo cunho biológico, foram refutadas, como destaca Schiebinger (2001, p. 272):

Em 1983, Gerald e Heide Schatten intensificaram esforços para revisar noções
fundamentais de fertilização num artigo apropriadamente intitulado 'The
Energetic Egg' [O Óvulo Energético]. Eles retrataram o óvulo, como o esperma,
como um agente ativo, dirigindo o crescimento de microviles (pequenas
projeções semelhantes a dedos sobre sua superfície) para capturar e amarrar
o esperma. Uma vez que o esperma é orientado na direção certa pelo óvulo,
sua cauda e enzimas digestivas (algumas das quais são ativadas pelo contato
com o óvulo) permitem que ele penetre o óvulo. O óvulo e o esperma são
retratados como 'parceiros' - talvez um par de carreira dupla - trabalhando
juntos no sentido de uma fertilização bem sucedida. Vale notar que o cone
de microviles do óvulo já fora documentado em 1895, mas só foi considerado
digno de pesquisa cerca de oitenta anos mais tarde.

Londa Schiebinger (SCHIEBINGER, 1987), em seu artigo Skeletons in the closet: the first illustrations of the female skeleton in eighteenth-century anatomy, problematiza as questões de desigualdade baseadas nas diferenças biológicas, abordando como o tamanho do crânio feminino, considerado inferior ao masculino, constituiria no campo científico a re(produção) de discursos sobre a suposta inferioridade da sua capacidade intelectual. A autora problematiza, também, os discursos que abordam o tamanho da pelve feminina, que por ser superior à dos homens, sinalizava um corpo destinado apenas à maternidade.

Portanto, como descrito anteriormente, nem a fisiologia ou a biologia, nem as explicações robustas do neurodesenvolvimento devem nos definir a finitude de um padrão de encaixe ou molde, muito menos nos condicionar a determinadas áreas do saber. E, por mais que essas informações ainda pareçam importantes, em determinadas pesquisas, reforçam ainda mais os efeitos discriminatórios que distanciam as mulheres dos campos acadêmicos e, particularmente, nas áreas de STEM.

Neste artigo utilizamos as estatísticas da participação e do desempenho de meninas e mulheres em disciplinas de STEM, nos diferentes níveis de ensino, contidas no relatório que está estruturado da seguinte forma: a primeira seção apresenta estatísticas da participação e do desempenho de meninas e mulheres em disciplinas de STEM nos diferentes níveis de ensino. A segunda seção fornece um modelo contextual para identificar fatores nos âmbitos individual, familiar, escolar e social, que influenciam a participação, o desempenho e o avanço das meninas na educação em STEM. A terceira seção identifica medidas que podem ser tomadas nesses diferentes âmbitos do modelo contextual, incluindo exemplos promissores que estão sendo desenvolvidos em todo o mundo. A seção final inclui as conclusões e um conjunto de recomendações-chave. 


\section{Unesco: decifrar o código}

A Organização das Nações Unidas para a Educação, a Ciência e a Cultura (UNESCO), criada em 16 de novembro de 1945, logo após a Segunda Guerra Mundial, com o objetivo de garantir a paz por meio da cooperação intelectual entre as nações, acompanhando o desenvolvimento mundial e auxiliando os Estados-Membro hoje são 193 países - na busca de soluções para os problemas que desafiam nossa sociedade, atua nas seguintes áreas: Educação, Ciências Naturais, Ciências Humanas e Sociais, Cultura, Comunicação e Informação. A organização se posiciona como uma instituição que tem como uma das prioridades a Educação, e acredita que, a partir dela, consegue-se construir uma sociedade com menos desigualdade, visando o desenvolvimento sustentável.

O texto Decifrar o código: educação de meninas e mulheres em STEM, a partir da chamada Agenda global 2030, indica 17 objetivos (ver figura 1) que buscam promover de diferentes formas a valorização à vida, ao trabalho, à dignidade e à igualdade, entendendo que assim se tornará mais provável alcançar o objetivo maior, que é a erradicação da fome. O texto é rico em dados estatísticos sobre gênero e Matemática e nos oferece um panorama geral do desenvolvimento feminino nessas áreas ao redor do mundo. Cabe-nos analisar e problematizar neste artigo que código é esse que deve ser decifrado? Por que uma organização como a Unesco envolveu-se com questões de gênero? Quais os resultados que observaram com a pesquisa em relação ao baixo índice de mulheres na Matemática? Qual a ligação entre a promoção da igualdade de gênero e a erradicação da fome mundial?

Um trecho interessante do documento diz respeito aos prêmios internacionais de pesquisa, como, por exemplo, o Prêmio Nobel, considerado uma das mais prestigiadas premiações do mundo. Anualmente, destacam-se pesquisas consideradas importantes nas áreas de Química, Física, Medicina, Literatura, Economia e negociações de Paz. Desde 1901, apenas 44 mulheres receberam o referido prêmio e, no que concerne às áreas STEM, de 589 prêmios, apenas 17 mulheres foram laureadas, o que representa menos de $3 \%$ dos premiados. Inicialmente, problematizamos o baixíssimo número de mulheres premiadas, pois, o mesmo texto da Unesco aponta que $28 \%$ de pesquisadores no mundo são mulheres, ou seja, não se trata só de ausência, mas de apagamento das pesquisadoras nas áreas de STEM.

A UNESCO, ao publicar esse documento oferece um lugar de destaque para reforçar discursos de empoderamento feminino e de inserção da mulher nas áreas ditas como masculinas. De acordo com o estudo, a limitação dos espaços femininos e a minoria discrepante de mulheres que contemplam as áreas exatas não ocorrem por acaso.

Segundo a UNESCO, para desconstruirmos essa realidade, primeiramente devemos entender os fatores que fabricam essa tendência. Para reverter essa situação, seria adequado iniciar esse processo de igualdade de gênero desde as séries iniciais nas escolas. Nesse sentido, formar docentes que reformulem os discursos que privam as mulheres de ocuparem certos espaços é fundamental, pois é papel das escolas e dos sistemas educacionais desempenhar uma função central que possibilite a autonomia de escolhas que não sejam marcadas apenas pelo gênero, promovendo também o interesse das meninas em todas as áreas, inclusive nas áreas de STEM. 
Conforme o documento, os primeiros traços da disparidade entre meninas e meninos no ensino de Matemática inicia-se nos primeiros anos da escolarização, como podemos perceber em diversas pesquisas na área, de autoras mulheres como Walkerdine (1995), Carvalho (2001), Souza e Fonseca (2010).

Valerie Walkerdine (WALKERDINE, 1995, p. 214) faz um estudo sobre garotas e Matemática, narrando que

A pesquisa que fiz sobre garotas e Matemática, revelou claramente as formas
pelas quais isso não é uma simples questão de as garotas fracassarem e os
garotos terem sucesso na Matemática. Na verdade, pode ocorrer de as garotas se
saírem bem e os rapazes, mal. Entretanto, as explicações do/a professor/a e dos/
as alunos/as a respeito desse desempenho eram extremamente interessantes.
Parecia haver um grande investimento na ideia de que o desempenho de sala
de aula não indicava o valor ou potencial verdadeiro no que respeitava aos
garotos, embora o oposto fosse verdadeiro a respeito das garotas.

A autora também explica que a produtividade das meninas na matemática era relacionada aos seus índices de disciplina e muito esforço, ou seja, uma menina ter um bom aproveitamento não tinha relação com seu raciocínio, mas, sim, com sua atitude de obediência em sala de aula.

Walkerdine (1995, p. 215) também usa como exemplo a fala de um professor e destaca a distinção de adjetivos que o educador usa para se referir a dois estudantes de 10 anos de idade: a menina, possuidora da melhor nota da turma e o menino, à beira da reprovação: "Uma trabalhadora muito, muito esforçada. Uma garota não particularmente brilhante... seu trabalho duro faz com que alcance o padrão." Sobre um garoto: "Ele mal pode escrever o seu nome... não porque ele não é inteligente não porque ele não é capaz, mas porque não pode sentar-se quieto, e não consegue se concentrar... muito perturbador... mas muito brilhante" (WALKERDINE, 1995, p. 215).

A fala do professor coloca a menina em uma posição de aluna esforçada e disciplinada, porém, por mais que possua a melhor nota da turma, ainda não ganha créditos por ser inteligente ou por possuir um bom raciocínio lógico. Já o menino é considerado com baixo índice de aprovação por ser indisciplinado, mas na visão do professor, ainda assim, é um aluno brilhante. Esse é um exemplo básico de como a sociedade, a escola e os próprios professores subestimam, inferiorizam e interferem na constituição e escolhas das meninas. É preciso considerar que há um processo histórico de produção de discursos sobre a inferioridade feminina que, de diferentes formas, em diferentes tempos, com diferentes práticas, interditou a presença das mulheres em lugares de saber/poder e, assim, a possibilidade delas em mostrar o quão inconcebível é a diferenciação desigual das capacidades intelectuais baseadas no sexo ou no gênero. Há de se considerar a visibilidade do discurso de práticas cotidianas de exercício de submissão generificados que marcam uma sociedade e da qual os professores são parte fundamentais, justamente pela potência da educação em mudar ou manter algumas realidades sexistas.

Souza e Fonseca (2010), ao pesquisarem os tipos de discursos contidos em uma sala de aula de EJA de uma comunidade de catadores, constataram que o enunciado "Homem é melhor em Matemática (do que mulher)" é o mais presente nas aulas de Matemática, e capturou frases ditas por meninos como: "Cê é muito burra", quando alguma menina não conseguia resolver algo ou "Cê é sabidona", quando respondiam 
algo corretamente e, até mesmo, "Ela não consegue aceitar que eu sou melhor que ela em conta", mostrando-se superior. A autora ainda destaca que

O enunciado da superioridade masculina para as contas circula também nas enunciações femininas. Por diversas vezes, as mulheres enfatizam a maior capacidade masculina para atividades matemáticas socialmente valorizadas, como é o caso de "contas de cabeça", seja nas lembranças das catadoras sobre como o pai fazia as contas (nunca a mãe), como ele guardava "tudinho de cabeça", ou na atualização da valorização dessa capacidade masculina para fazer contas de cabeça, quando o recurso é utilizado por dois catadores e valorizado por elas (SOUZA; FONSECA, 2010, p. 53).

As autoras comentam que os homens multiplicam enunciações que se referem a uma superioridade masculina, e que as mulheres as reproduzem. O enunciado não circula apenas entre estudantes, mas persiste também nas falas e atitudes de professores/as, quando, por exemplo, ao fazerem um questionamento, incentivam e esperam a participação masculina, acolhendo melhor as respostas dadas pelos homens. Nesse sentido, a negociação de sentidos 'tradicionais' de como homens e mulheres, meninos e meninas, posicionam-se frente à Matemática passa despercebida se não há um esforço analítico da linguagem, das formas e das práticas discursivas.

Justamente essa "[...] inconformidade e desencanto em relação aos tradicionais arranjos sociais e políticos, às grandes teorias universais, ao vazio formalismo acadêmico, à discriminação, à segregação e ao silenciamento" (LOURO, 2007, p. 16) foi visível a partir das tensões sociais e políticas que ocorreram, principalmente em países como a França, os Estados Unidos, a Inglaterra e a Alemanha em 1968. Historicamente, nessa época, pairava um discurso em torno dessas questões que possibilitaram que o 'grito' de que havia uma necessidade de se falar sobre as mulheres fosse conhecido como segunda onda do movimento feminista.

A grande repercussão da Guerra do Vietnã, a morte de Che Guevara na Bolívia, ocorrida em outubro de 1967, o assassinato do líder negro Martin Luther King e as mulheres queimando sutiãs no conhecido protesto Bra-Burning são fatos que pesaram na explosão de 1968, como uma espécie de fissão nuclear espontânea que abalou as instituições e regimes. Em outubro desse ano emblemático, enquanto Jordi Ford era eleita Miss América, do lado de fora do teatro mais de uma centena de mulheres protestavam contra a ditadura da beleza que estava sendo imposta às mulheres na época. Elas vieram de vários estados americanos e saíram às ruas de Atlantic City levando símbolos de feminilidade da época: cílios postiços, revistas femininas, sapatos de saltos altos e sutiãs.

A expressividade não estava somente nos atos públicos, mas também se encontrava por meio de livros, jornais e revistas. Era necessário firmar a materialidade desse grito feminino por elas mesmas: falarem e, mais do que isso, serem ouvidas. Assim, o livro escrito por Simone de Beauvoir - O segundo sexo -, lançado em 1949, trouxe à tona, no movimento feminista, uma discussão que se desenrolou posteriormente e até hoje é um tema central: a questão da desnaturalização do ser mulher.

Ao iniciar o segundo volume de seu livro, Beauvoir $(1967$, p. 9) escreve "[...] não se nasce mulher, torna-se mulher", trazendo a possibilidade de se pensar a feminilidade não como algo "natural" ou "biológico", mas como uma construção social. É nesse contexto que o conceito de gênero começa a adentrar as principais discussões. 
O termo foi utilizado pela primeira vez por um psicanalista da Universidade da Califórnia chamado Robert Stoller, ao participar de um projeto que pesquisava transexuais. Ele apresentou o termo - identidade de gênero - no Congresso Internacional de Psicanálise, em 1963, na cidade de Estocolmo (FERREIRA, 2009).

Era necessário trazer a construção e a reprodução das relações desiguais para o campo social. Não era mais permissível que as justificativas para as desigualdades se pautassem somente nos aspectos biológicos, era necessário buscar as justificativas “[...] nos arranjos sociais, na história, nas condições de acesso aos recursos da sociedade, nas formas de representação" (LOURO, 2007, p. 22). Buscou-se, então, a utilização do gênero como um aspecto relacional entre homens e mulheres; dessa forma, não se poderia compreender qualquer um dos sexos por meio de estudos isolados e estreitos, focados somente na mulher ou no homem (SCOTT, 1995). Scott (1995, p. 75) ainda destaca:

O termo gênero, além de substituto para o termo mulheres, é também utilizado para sugerir que qualquer informação sobre as mulheres é necessariamente informação sobre os homens, que um implica o estudo do outro. Essa utilização enfatiza o fato que o mundo das mulheres faz parte do mundo dos homens, que ele é criado nesse e por esse mundo masculino.

O gênero, como categoria de análise, é compreendido como "[...] um mecanismo por meio do qual se produzem e se naturalizam as noções de masculino e de feminino" (BUTLER, 2006, p. 70, tradução nossa). Um exemplo de normalizador e regulador é o currículo. O currículo naturaliza o que é feminino e masculino, regula condutas do ser homem e mulher nas escolas, ou seja, legitima o normal e o anormal nas condutas generificadas.

É importante visibilizar as produções acadêmicas sobre o currículo, que não se limita a uma listagem de conteúdo ou a uma educação enciclopédica. Hoje entendemos que o currículo é uma 'arena de lutas' que, mais do que ensinar conhecimentos de áreas específicas, produz subjetividades e impacta os nossos modos de ser no mundo. O currículo é, então, um processo escolar constituído por formações discursivas e não discursivas, como nos explica Silva (2015), em seu livro Documentos de identidade.

O autor escreve sobre o currículo em uma perspectiva das desigualdades e caracteriza-o como um documento norteador do ensino, possuidor de características predominantemente masculinas, sendo um forte produtor do discurso patriarcal. Ele também problematiza que a solução para esse problema não seria invertê-lo e torná-lo com características femininas, mesmo porque tudo que se entende hoje por características de gênero está constituído e controlado dentro dessa sociedade patriarcal, mas sim cultivar e priorizar novas políticas para ambos os sexos.

O currículo oficial valoriza a separação entre sujeito e conhecimento, o domínio e o controle, a racionalidade e a lógica, a ciência e a técnica, o individualismo e a competição. Todas essas características refletem as experiências e os interesses masculinos, desvalorizando, em troca, as estreitas conexões entre quem conhece e o que é conhecido, a importância das ligações pessoais, a intuição e o pensamento divergente, as artes e a estética, o comunitarismo e a cooperação - características que estão, todas, ligadas às experiências e aos interesses das mulheres (SILVA, 2015, p. 94). 
Retomar as teorias de currículo em suas diferentes abordagens serve-nos como marcação teórica do entendimento do currículo como "[...] aquilo que fazemos as coisas, mas, sobretudo, aquilo que as coisas que fazemos fazem a nós" Silva (2015, p. 194). O docente e sua subjetividade constituem o processo de ensino e de aprendizagem. Por isso, conhecer a formação de nossas práticas sociais é importante, de forma geral, mas, especificamente, nas noções de gênero, é fundamental.

As diferenças entre os gêneros, segundo Citeli (2001), são separadas em dois eixos: o biológico e o social. Neste artigo, a partir dos dados do documento, nós direcionamos a análise para a parte social e educacional da desigualdade.

Silva (2015), em sua análise sobre a teoria do currículo, afirma que o conceito de gênero segue uma trajetória semelhante a do conceito de classe. Conta que

As perspectivas críticas sobre currículo tornaram-se crescentemente questionadas por ignorarem outras dimensões de desigualdade que não fosse aquelas ligadas a classe social. Especificamente, questionavam-se as perspectivas críticas por deixarem de levar em consideração o papel do gênero e da raça no processo de produção e reprodução da desigualdade (SILVA, 2015, p. 91).

Promovendo a igualdade de gênero, seguindo a mesma linha enfrentada pelas lutas de classe, tomando como solução uma educação, temos como ponto de intersecção a problemática inicial que poderia estar na base dos problemas de desigualdade, a falta de possibilidade de acesso. Silva (2015, p. 92) complementa:

Estava claro, para essa análise, que o nível de educação das mulheres, em
muitos países, sobretudo naqueles situados na periferia do capitalismo, era
visivelmente mais baixo que o dos homens, refletindo seu acesso desigual
às instituições educacionais. Mesmo naqueles países em que o acesso era
aparentemente igualitário, havia desigualdades internas de acesso aos recursos
educacionais: os currículos eram desigualmente divididos por gênero. Certas
matérias e disciplinas eram consideradas naturalmente femininas. Da mesma
forma, certas carreiras e profissões eram consideradas monopólios masculinos,
estando praticamente vedadas às mulheres.

Ou seja, além do difícil acesso feminino à educação, as meninas enfrentam desigualdades internas, legitimadas na sociedade patriarcal, desde o entendimento de quais profissões possíveis para cada gênero até a reprodução de discursos que inferiorizam mulheres em quaisquer profissões que exerçam.

De acordo com a revista digital The São Paulo Times (ENTENDA..., 2014), a mulher além de esposa, dona de casa e mãe, também ocupa seu espaço no mercado de trabalho. De acordo com um estudo divulgado pela Fundação Carlos Chagas (1976), apenas $29 \%$ das mulheres brasileiras trabalhavam. No entanto, o número subiu para $40 \%$ em 2000 e chegou a $53 \%$ em 2007, um crescimento surpreendente.

Segundo dados do IBGE (2009), a porcentagem de mulheres que estão inseridas no mercado de trabalho e que declaram também cuidar dos afazeres domésticos chega a quase $90 \%$, contra $46,1 \%$ dos homens. A diferença continua, no tempo em que os entrevistados disseram dedicar-se a essas tarefas: enquanto eles gastam em média 9,2 horas por semana, elas comprometem 20,9 horas semanais, ou seja, a carga horária feminina de afazeres domésticos é mais do que o dobro da carga horária masculina; equivalente a um segundo emprego, só que sem remuneração. Antes da década de 
1990, o IBGE não tinha dados estatísticos que comparassem as mulheres aos homens, porque eram totalmente invisibilizadas, inclusive nas estatísticas do Estado.

Já a revista Época publicou (EM..., 2018) que em 15 anos o número de famílias chefiadas por mulheres dobrou. De acordo com estudo elaborado pelos demógrafos Suzana Cavenaghi e José Eustáquio Diniz Alves, coordenado pela Escola Nacional de Seguros, o contingente de lares em que elas tomam as principais decisões saltou de 14,1 milhões, em 2001, para 28,9 milhões, em 2015 - aumento de 105\%.

Antigamente, o índice de mulheres líderes de família era influenciado pelo avanço de famílias com uma pessoa só, sem filhos. Família, segundo o IBGE (2010), é o conjunto de pessoas ligadas por laços de parentesco, dependência doméstica, ou normas de convivência residentes na mesma unidade domiciliar, ou pessoa que more só em uma unidade domiciliar; neste caso chama-se família unipessoal.

A vulnerabilidade social da mulher é associada à cultura da sociedade patriarcal, ou seja, a mulher, quando líder de família, só estaria nessa posição caso o marido a tivesse abandonado, e não por suas próprias escolhas. Mas, atualmente, a realidade é outra, embora a maior parte das líderes de família sejam aquelas que vivem sozinhas com seus filhos (um contingente de 11,6 milhões de pessoas). A principal mudança estatística foi o aumento significativo do comando feminino em famílias em que há um cônjuge. Entre as famílias tradicionais compostas por um casal, o número de mulheres líderes passou de 1 milhão, em 2001, para 6,8 milhões, em 2015, alta de 551\%. Já no caso dos casais sem filhos, o crescimento foi ainda maior: de 339 mil para 3,1 milhões, salto de $822 \%$.

Levando em consideração esses dados, que estão em constante progressão, e sabendo que a população feminina é a maioria da população mundial, podemos justificar e entender os objetivos da UNESCO ao investir no desenvolvimento das mulheres, que estão, cada vez mais, ocupando o espaço de líderes em suas famílias, provendo, assim, o sustento do lar e, consequentemente, sendo peças fundamentais para a erradicação da fome mundial.

Para fazermos a análise do documento, devemos entender qual a representação das estatísticas. Sobre estatística, Battisti e Battisti (2008, p. 9) explicam

Você já ouviu a palavra "Estatística"? O que você lembra quando escuta esta palavra? O que você lembra quando ouve a palavra probabilidade? Se você respondeu números, gráficos, tabelas, contas, então acertou em parte, pois a Estatística é muito mais que isso. Além de fornecer métodos para gerar tabelas e gráficos e produzir resultados por meio de contas, a Estatística também dispõe de métodos para coletar dados e auxiliar na análise destes.

Segundo Foucault (2008, p. 138), as estatísticas mostram as regularidades das populações: dados quantitativos sobre o número de mortes, doentes e acidentes. Logo, a estatística é um tipo de saber fundamental para a construção de uma base sólida de dados sobre os fenômenos da população. O controle populacional é feito estatisticamente, por isso esse processo pode ser visto como um método matemático que tem como objetivo controlar, medir, regular, toda e qualquer atitude e desenvolvimento de uma sociedade. Battisti e Battisti (2008) completam que a Estatística fornece métodos para a coleta, organização, análise e interpretação de dados. Apresentaremos neste capítulo as estatísticas que legitimam as informações contidas no já citado documento da Unesco. 


\section{Participação e avanços nas áreas de STEM: análise estatística}

Ao analisarmos os dados estatísticos contidos no documento, podemos ter um panorama geral de como está o desenvolvimento de meninas e mulheres nas áreas de STEM. Em um primeiro momento, é interessante olharmos para questões como o acesso do sexo feminino nas escolas. Abaixo analisamos o primeiro usado pela Unesco:

Figura 3 - Taxa de matrículas de meninas e mulheres, por nível de ensino, média mundial

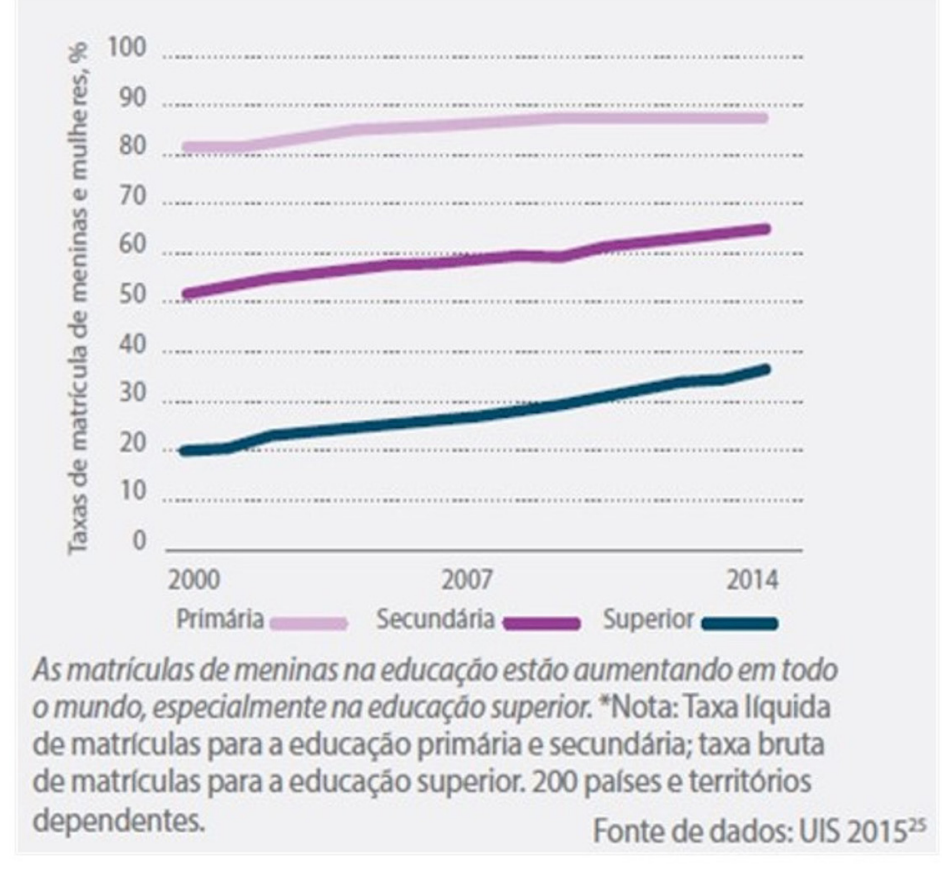

Fonte: UNESCO (2018).

Nesta figura de análise, temos as taxas de matrículas na educação, de meninas e mulheres, separadas por níveis de ensino, ao redor do mundo. No primeiro momento, podemos perceber que o índice vem sendo progressivo: de 2000 até 2014 a taxa progrediu, porém não houve um avanço significativo de um nível para outro. 0 número de mulheres inscritas no ensino secundário, referente ao ensino primário cai, e o mesmo acontece com o índice de mulheres no ensino superior: o número também diminui. No ano 2000 , dos $80 \%$ de mulheres inseridas no ensino primário, $50 \%$ ingressam no ensino secundário e restam $20 \%$ para o ensino superior. Já no ano de 2014, os índices estão mais elevados e mais próximos, indicando que quase $90 \%$ das mulheres são inseridas no primário, e quase $40 \%$ chegam às universidades. De 2000 até 2014 percebe-se um aumento de 20\% de mulheres no Ensino superior, ou seja, a progressão é constante e, por mais lento que seja o processo de equalização numérica, ele está em funcionamento frágil e incipiente demais diante de números assustadores de violência contra a mulher, por exemplo.

De acordo com o documento, essas mulheres que ingressam nos cursos superiores optavam por campos de Educação, Arte, Saúde, Bem-estar, Humanidades, Ciências Sociais, Jornalismo, Negócios e Direito, e os homens optavam por Engenharia, produção industrial, construção e tecnologias. Na situação atual, as mulheres estão em maior proporção que os homens em cursos de Ciências Naturais, Matemática e Estatística, havendo um aumento significativo de matrículas entre 2000 e 2015. 
Figura 4 - Parcela de estudantes de ambos os sexos, média mundial, matriculados na educação superior, por campo de estudo

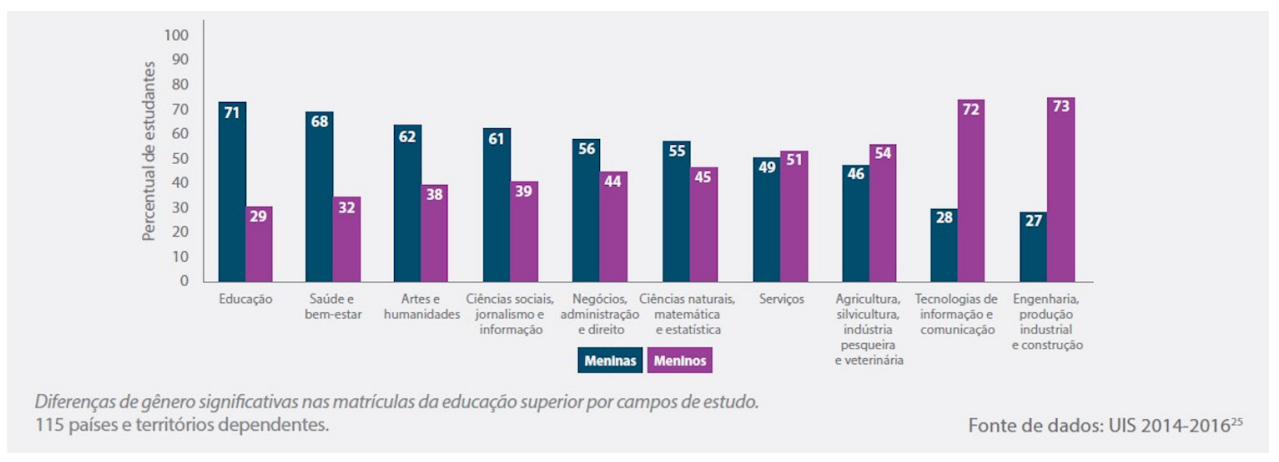

Fonte: UNESCO (2018).

Ao observamos essa tabela, podemos destacar que os cursos que possuem superioridade masculina giram em torno da Agricultura, Tecnologia e Engenharia, ou seja, das áreas de STEM. Apenas a área da Matemática foi superada pelo sexo feminino; as outras áreas relacionadas ainda não ultrapassaram o masculino.

Então nos cabe problematizar: se o número de mulheres na área da Matemática superou o dos homens, por que a quantidade de mulheres ganhadoras de prêmios renomados na área está estagnada e muitas vezes até mesmo inexistente? A medalha Fields, por exemplo, é o prêmio destaque da área da Matemática, equivalente ao Nobel das outras áreas. Entregue a cada quatro anos, durante o Congresso Internacional de Matemática (ICM), a notáveis e promissores matemáticos(as), com até 40 anos de idade. Concedida pela primeira vez em 1936, a Láurea é um reconhecimento a trabalhos de excelência e um estímulo a novas realizações. De 1936 até 2019, foram 60 laureados no total; dentre os 60, apenas uma mulher, Maryam Mirakhani.

Maryam nasceu no Irã e em sua infância sonhava em ser escritora, mas foi no ensino médio que o interesse pelos números, influenciada por seu irmão, floresceu. Maryam, em 1995, iniciou o bacharelado em Matemática e foi medalhista na Olimpíada Internacional; em 2004 recebeu o título de phD pela Universidade de Harvard. Além disso, Maryam casou-se e teve uma filha. Atuou em várias áreas de pesquisa como geometria algébrica, geometria diferencial, sistemas dinâmicos, probabilidade e topologia de baixa dimensão. Em 2014, tornou-se a primeira mulher a ganhar a Medalha Fields.

No livro História de Hipátia e de muitas outras matemáticas, escrito por Cecília de Souza Fernandez, Ana Maria do Amaral e Isabela Viana em 2019, as autoras contam a história de algumas mulheres importantes na área da Matemática, visibilizando, assim, suas histórias e contribuições, iniciando por Hipátia, que é considerada a primeira mulher Matemática, e finalizando com Maryam, exemplo contemporâneo de mulher Matemática, pesquisadora e mãe. As autoras defendem que uma das maiores dificuldades para motivar uma estudante a tornar-se Matemática é a falta de exemplos, e o livro, contendo alguns deles, pode ser considerado um dispositivo de visibilidade (PEREIRA, 2019), tal como o prêmio L'Oreal para Mulheres na Ciências.

Neste contexto de motivação, outro gráfico do documento da Unesco que cabe analisar aqui, é sobre as expectativas dos jovens com 15 anos de idade, em relação às carreiras científicas que desejam seguir. 
Figura 5 - Expectativas dos estudantes de 15 anos de idade quanto às carreiras relacionadas às ciências, por subcampo de estudo

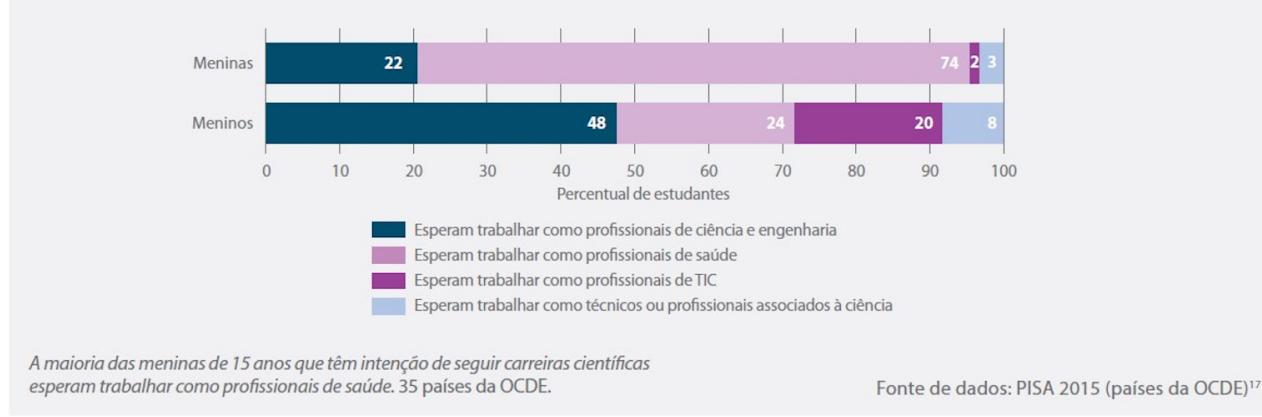

Fonte: UNESCO (2018).

Ao analisarmos esse gráfico, destacamos o alto índice de adolescentes do sexo feminino que esperam trabalhar como profissionais da saúde (74\%), um percentual que nos remete ao discurso patriarcal, que posiciona a mulher nas profissões de cuidado ou com um viés maternal.

\section{Análise da aprendizagem em educação de STEM}

O maior envolvimento de meninas na área da Matemática em relação aos meninos varia de acordo com a região. No documento, as análises foram feitas em diversos países ao redor do mundo, dentre eles estão contemplados os países da América Latina, da África, tendo algumas lacunas na Ásia, ocorridas pela falta de dados disponíveis. Os gráficos abaixo mostram a realidade de gênero.

Figura 6 - Diferença de gênero no desempenho em Matemática, $4^{\circ}$ ano

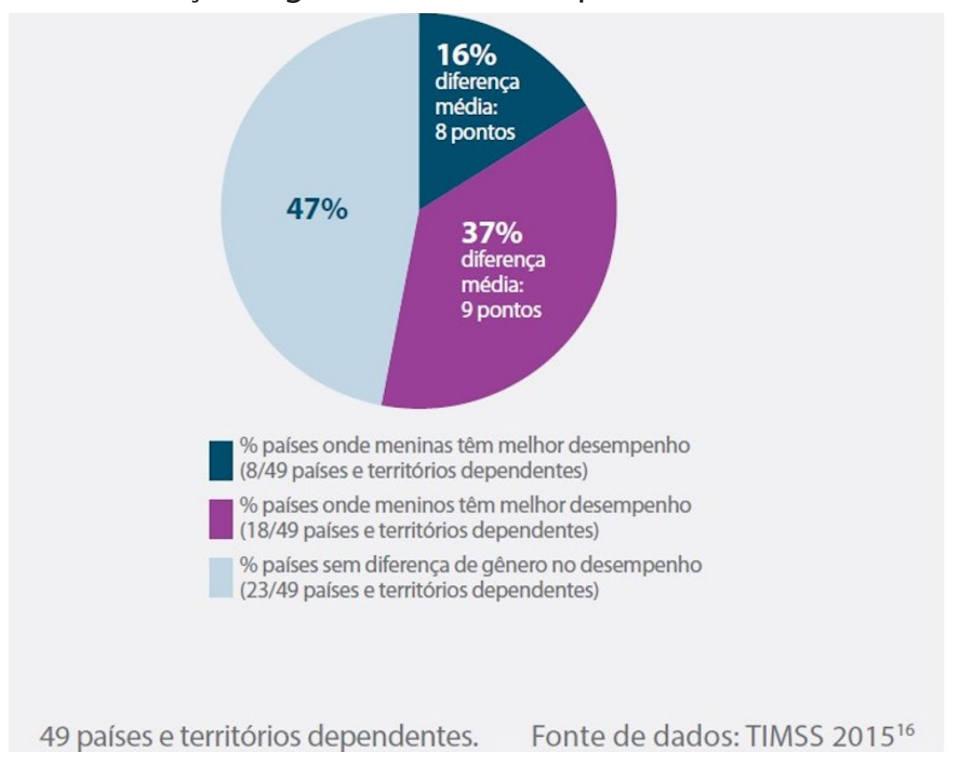

Fonte: UNESCO (2018).

Os desempenhos variam muito de acordo com a região mencionada. No gráfico acima temos a porcentagem dos alunos de $4^{\circ}$ ano, indicando que $47 \%$ dos países pesquisados não possuem uma relevante diferença entre meninos e meninas no rendimento em Matemática. Já entre a diferença de pontuação entre meninos e meninas no $3^{\circ}$ e no $6^{\circ}$ ano, o documento revela que a pontuação dos meninos é superior na maioria dos países pesquisados. 
A diferença de desempenho matemático no $8^{\circ}$ ano já é menos impactante, pois $67 \%$ dos países não possuem diferença de gênero.

Figura 7 - Diferença de gênero no desempenho em matemática, $8^{\circ}$ ano

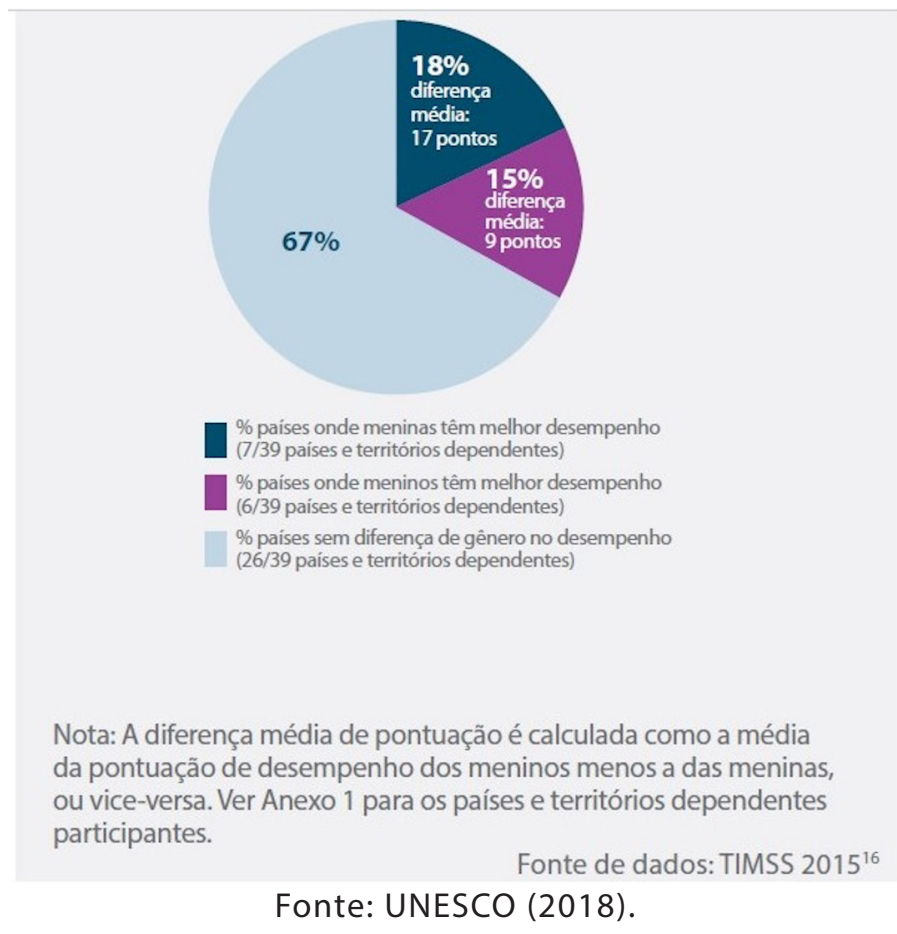

Vale destacar que essa análise do desempenho feminino e masculino na Matemática depende de muitas variáveis, dentre elas estão as diferenças regionais e culturais, e também o nível e faixa etária dos alunos pesquisados.

\section{Fatores que influenciam a participação, o avanço e o desempenho de meninas e mulheres na educação de STEM}

São múltiplos os fatores que podem ser influenciadores de meninas e mulheres a se interessarem pelas áreas de STEM, particularmente pela Matemática. O documento revela que os principais influenciadores são compostos por quatro âmbitos: individual, familiar, escolar e social. Abaixo apresentamos o quadro utilizado pelo documento para exemplificar os fatores.

Figura 8 - Marco contextual dos fatores que influenciam a participação, o desempenho e o avanço de meninas e mulheres nos estudos de STEM

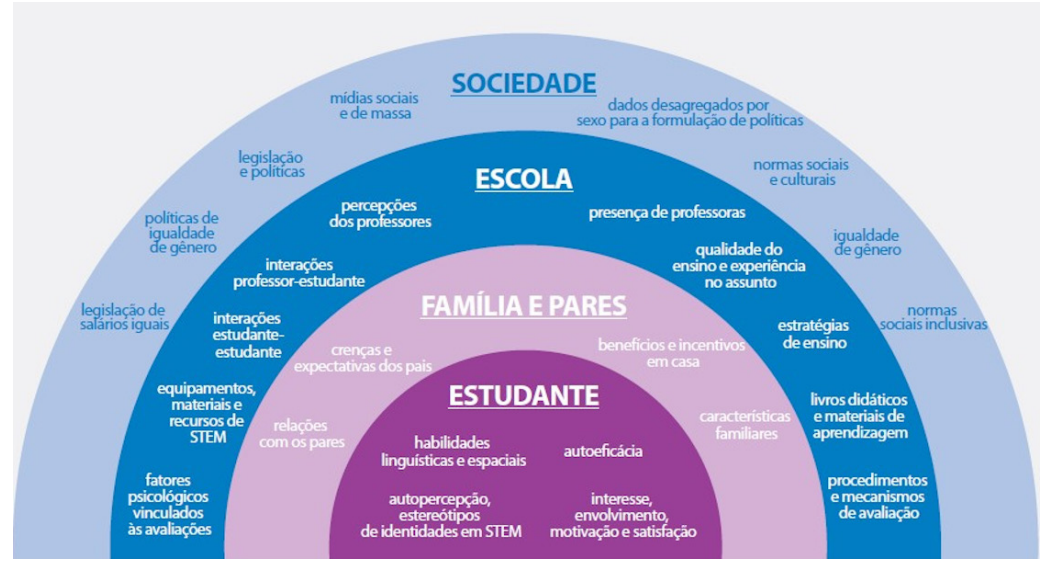

Fonte: UNESCO (2018). 
$\mathrm{Na}$ figura 8 temos os quatro âmbitos destacados, os quais apresentam subfatores influenciadores de meninas e mulheres: (a) Estudante: habilidades linguísticas e espaciais, autoeficácia, autopercepção, estereótipos de identidades em STEM, interesse, movimento, motivação e satisfação; (b) Família e pares: crenças e expectativas dos pais, relação com os pares, benefícios e incentivos em casa, características familiares; (c) Escola: fatores psicológicos vinculados às avaliações, equipamentos materiais e recursos de STEM, interações estudante-estudante, interações professor-estudante, percepção dos professores, presença dos professores, qualidade do ensino e experiência no assunto, estratégias de ensino, livros didáticos e materiais de aprendizagem, procedimentos e mecanismos de avaliação; (d) Sociedade: legislação de salários iguais, políticas de igualdade de gênero, legislação e políticas, mídias sociais e de massa, dados desagregados por sexo para a formação de políticas, normas sociais e culturais, igualdade de gênero, normas sociais inclusivas.

Já os fatores psicológicos são grandes influenciadores na negação das escolhas femininas pelas áreas de STEM, porque as meninas passam por um processo de autosseleção e, muitas vezes, não consideram que certas profissões são compatíveis com seu gênero. Os estereótipos de gênero são muito presentes em todo o âmbito social, escolar e familiar e isso afeta negativamente o interesse das meninas por certas áreas do conhecimento, por acreditarem que algumas áreas são exclusivamente masculinas, como as áreas que possuem cálculos e acabam por não se identificarem com engenharias e Matemática, por exemplo.

O âmbito familiar é geralmente influenciado pelos pais, ou seja, os pais são responsáveis pela formação de pensamentos, atitudes e interesses de seus filhos. Se os pais possuem opiniões sexistas por sua estrutura cultural e seguem a linha de educação baseada no patriarcado, terão uma diferença entre a criação dos filhos e das filhas. Os fatores socioeconômicos, socioculturais, e a escolaridade dos pais são fatores que também influenciam na educação e escolhas femininas.

O âmbito escolar é o fator principal nas escolhas de todos os seus alunos. $O$ documento afirma que escolas com docentes qualificados, que possuem especialização em ciências e Matemática podem influenciar, de forma positiva, o envolvimento de meninas nas áreas de STEM. Professoras também são figuras exemplares e podem servir de espelho, motivando e neutralizando os estereótipos de gênero relativos às habilidades em STEM.

E por último, no âmbito social, temos que os países com maior igualdade de gênero possuem menor disparidade no sucesso das áreas mencionadas, ou seja, as normas culturais são influenciadoras.

\section{Considerações finais}

Enfim, ao analisarmos o documento, chegamos às seguintes considerações: primeiramente, tal como outras autoras, o documento mostra que as divergências de gênero na participação de STEM iniciam-se nas séries iniciais, em brincadeiras relacionadas às ciências e à Matemática, no discurso dos professores, no currículo, e até mesmo em livros infantis estereotipados, constituindo uma herança cultural manifestada em práticas cotidianas de exclusão, silenciamento e condução de condutas. 
Estatisticamente, as meninas perdem o interesse por STEM no decorrer do tempo, com o aumento da idade, principalmente na adolescência, o que interfere nas suas escolhas quando optam por determinados cursos na universidade, ocasionando a presença de apenas $35 \%$ de mulheres nos campos de STEM.

Há uma diferença regional quando se fala de gênero e inserção das mulheres em campos ditos como privados. A representatividade feminina varia de acordo com a região, levando em consideração a parte cultural de cada país.

A desistência e abandono das mulheres aos estudos na educação superior, na transição para o mundo do trabalho e até mesmo durante a carreira profissional é desproporcional. Os motivos podem ser diversos, porém, o maior motivo mencionado do abandono da carreira profissional pelas mulheres é a dedicação para a maternidade.

Temos quatro âmbitos que são influenciadores nas escolhas das meninas e mulheres, e é a partir deles que podem surgir intervenções para desconstruir a realidade da minoria feminina nas áreas de STEM, incentivando as meninas, cada vez mais, a darem suas contribuições para o desenvolvimento equalizado da sociedade.

Fome de quê? É uma provocação à desconstrução aos discursos machistas, já que identificamos que as divergências de gênero na participação de STEM não são por acaso. Também mostramos que as meninas perdem o interesse pela Matemática no decorrer do tempo, com o aumento da idade, principalmente na adolescência. No documento da Unesco, as diferenças regionais são expostas quando se fala em inserção das mulheres nos campos ditos privados. E, por último, reforçamos que os quatro âmbitos (sociedade, escola, família e estudante) são os principais influenciadores nas escolhas das meninas e mulheres e, é a partir deles que podem surgir intervenções para desconstruir essa realidade de minoria feminina nas áreas de STEM.

Nossa perspectiva, ao analisar o documento da Unesco, foi entender essa disparidade em termos estatísticos, que nos diz muito, mas, por outrolado, compreender que a estatística esconde mais do que mostra quando se trata de educação de meninas. Precisamos partir da visibilidade estatística para construir elos e desconstruir práticas sociais que ampliam a participação e desnudem a dinâmica da valorização dos grandes prêmios que, enquanto dispositivos de visibilidade, inviabilizam a potência criadora das mulheres.

\section{Referências}

BATTISTI, I. D. E.; BATTISTI, G. Métodos estatísticos. Ijuí: Ed. Unijuí, 2008.

BEAUVOIR, S. O segundo sexo. Rio de Janeiro: Nova Fronteira, 2009.

BEAUVOIR, S. O segundo sexo: experiência vivida. São Paulo: Difusão Europeia do Livro, 1967.

BUTLER, J. Deshacer el género. Barcelona: Paidós, 2006.

CARVALHO, M. P. Mau aluno, boa aluna?: como as professoras avaliam meninos e meninas. Revista Estudos Feministas, Florianópolis, v. 9, n. 2, p. 554-574, 2001. DOI: https://doi.org/fprp2m.

CITELI, M. T. Fazendo diferenças: teorias sobre gênero, corpo e comportamento. Revista Estudos Feministas, Florianópolis, v. 9, n. 1, p. 131-145, 2001. DOI: https://doi.org/b4jdcs.

EM 15 anos, número de famílias chefiadas por mulheres mais que dobra. Época, Rio de Janeiro, 6 mar. 2018. Disponível em: https://cutt.ly/AE7JQEn. Acesso em: 12 mar. 2020. 
ENTENDA como anda a porcentagem de mulheres no mercado de trabalho nos últimos 30 anos. The São Paulo Times, 1 jun. 2014. Disponível em: https://cutt.ly/1E7Haui/. Acesso em: 20 maio 2020.

FERNANDEZ, C. S.; FASSARELLA, A. M. L.; VIANA, I. V. A história de Hipátia e de muitas outras matemáticas. Rio de Janeiro: Copyright, 2019.

FERREIRA, M. O. O impacto dos estudos de gênero sobre a construção do pensamento social: primeiras aproximações. In: CICLO DE ESTUDOS EDUCAÇÃO E FILOSOFIA, 5., 2009, Pelotas, RS. Anais [...]. Pelotas: IF-Sul. 2009.

FOUCAULT, M. Segurança, território e população. São Paulo: Martins Fontes, 2008.

FUNDAÇÃO CARLOS CHAGAS. Banco de dados sobre o trabalho das mulheres. São Paulo: FCC, [1976]. Disponível em: https://www.fcc.org.br/bdmulheres/index.php?area=home. Acesso em: 12 maio 2020.

IBGE. Censo brasileiro de 2010. Rio de Janeiro: IBGE, 2010.

IBGE. Estatística de gênero. Rio de Janeiro: IBGE, 2009.

LOURO, G. L. Gênero, sexualidade e educação: uma perspectiva pós estruturalista. 9. ed. Petrópolis: Vozes, 2007.

NAÇÕES UNIDAS BRASIL. Sobre o nosso trabalho para alcançar os objetivos de desenvolvimento sustentável no Brasil. Brasília: Casa ONU Brasil, c2021. Disponível em: https://brasil.un.org/pt-br/ sdgs. Acesso em: 20 out. 2021.

PEREIRA, J. C. A inserção das mulheres na ciência: efeito de um dispositivo de visibilidade. 2019. Tese (Doutorado em Ensino de Ciências) - Universidade Federal do Rio Grande do Sul, Porto Alegre, 2018. Disponível em: http://hdl.handle.net/10183/210787. Acesso em: 7 out. 2021.

SCHIENBINGER, L. O feminismo mudou a ciência? Bauru: Edusc, 2001.

SCHIEBINGER, L. Skeletons in the closet: the first illustrations of the female skeleton in eighteenth-century anatomy. In: GALLAGHER, C.; LAQUEUR, T. The making of the modern body: sexuality and society in the nineteenth century. Berkeley: University of California Press, 1987. p. 42-81.

SCOTT, J. W. Gênero: uma categoria útil de análise histórica. Educação \& Realidade, Porto Alegre, v. 20, n. 2, p. 71-99, 1995. Disponível em: https://seer.ufrgs.br/index.php/educacaoerealidade/ article/view/71721. Acesso em: 6 out. 2021.

SILVA, T. T. Documentos de identidade: uma introdução às teorias do currículo. 3. ed. Belo Horizonte: Autêntica, 2015.

SOUZA, M. C. R. F.; FONSECA, M. C. F. R. Relações de gênero, educação matemática e discurso: enunciados sobre mulheres, homens e matemática. Belo Horizonte: Autêntica, 2010.

THOMSON, J. A.; GEDDES, P. The evolution of sex: with 104 illustrations. London: Walter Scott, 1889. Disponível em: https://wellcomecollection.org/works/qcajbycg/items?canvas=11. Acesso em: 6 out. 2021.

UNESCO. Decifrar o código: educação de meninas e mulheres em ciências, tecnologia, engenharia e matemática (STEM). Brasília: Unesco, 2018. Disponível em: https://cutt.ly/AE7YVIQ. Acesso em: 5 out. 2021.

WALKERDINE, V. O raciocínio em tempos pós-modernos. Educação e Realidade, Porto Alegre, v. 2, n. 20, p. 207-26, 1995. Disponível em: https://seer.ufrgs.br/educacaoerealidade/article/ view/71742. Acesso em: 6 out. 2021. 